\title{
Recycling heat energy - Prolonging the lifetime of industry's most invaluable resource
}

\author{
Philip Donnellan
}

Process and Chemical Engineering, UCC

Intellectuals solve problems; geniuses prevent them (Albert Einstein)

Drive home from work. . . lights on. . . dinner in oven. . . kettle boiling. . TV on.... Without energy as we know it, January might just become a little bit harder.

\section{What is energy?}

Energy is everywhere and in everything. It has become a hot topic of conversation, a buzzword which is used in every political campaign and every report on the decaying state of our environment. Statements such as "Energy is running out", have become so common that they are more likely to make you change the channel than pay attention. Nobody wants to hear it, but the unfortunate thing is that we do actually have an energy problem.

Before discussing it, it is very important to examine the word energy more closely. Energy is not running out. That is not a dramatic statement, but simply an example of how buzzwords and the use of generic terms in media reports can give a false meaning to perfectly simple statements. Energy is all around us. The desk I am writing on contains energy, the motion of my fingers over the keyboard is a type of energy conversion as is every breath I take. With no energy, it is theorized that all matter as we know it could simply disintegrate into a collection of subatomic particles. No, energy is not running out at any point in the near future. What people really mean when they talk about energy is useful, high value energy such as electricity. These sources are primarily derived from naturally occurring products such as coal, oil or gas, substances which are created extremely slowly over very long periods of time. But why use these energy sources? We have just said that energy is contained everywhere, and by everything, so why limit ourselves to using non-renewable substances like oil to provide our electricity? To understand this, we need to look at how energy moves and how we use it. 


\section{How do we use energy?}

If we look at the amount of energy contained in a substance, we can refer to its energy density as being the amount of energy a very small piece of it contains (for any engineers or scientists, the type of energy I am referring to here is specific entropy), i.e.: something with a high energy density contains a large amount of useful energy (for example a can of petrol). An easy way of understanding how energy moves is to picture water flowing freely down a hill. The water will flow down but not up the hill, and similarly when it comes to energy, energy can be made "flow" from a high energy density to a low energy density (this is a slight oversimplification but it makes my point). Temperature is the most common representation of energy, something with a high temperature generally contains a large amount of energy. Thus a simple example of how energy flows is the use of a radiator. If you want to heat yourself up, a radiator is only useful if it is hot. If it is hot, then by putting your hand up against it you will feel a warm sensation. This is simply energy flowing from the high temperature of the radiator to the low temperature of your hand. If the radiator is cold, you might feel the cooling sensation of energy flowing from your hand to the radiator, as this is now at a lower temperature than your body.

In everyday life, we rely on energy conversions and transfers to make things happen for us. The lightbulb works by converting electrical energy (high energy density) into light energy (low energy density), a car works by converting the energy contained in petrol (high energy density) into movement of the car (low energy density). This is why we cannot use most of the energy freely available in the world around us to run our television sets or heat up our dinners. We need something with a very high energy density, such as electricity or very hot substances, to do these things for us. We refer to these high energy density substances as high value energy sources. Electricity and hot substances are not (generally) freely available in the world. That is why coal, oil and gas (these have exceptionally high energy densities) are used to create them. As we currently rely heavily upon these non-renewable substances as our primary energy sources, we must monitor our energy consumption and limit our usage to prevent future shortages.

\section{We are using more high value energy than we can afford!}

In industry, vast quantities of high value energy are being used every day. The two main types of high value energies needed are electricity (for running equipment etc.) and high temperature heat energy (for heating up tanks etc.). Due to its size, this sector represents a very large fraction of the total energy consumed throughout the world. Unfortunately, it also represents a large source of energy wastage. It has been reported that about half of the high value energy entering into the American Manufacturing industry is eventually being dumped into the atmosphere as waste heat. In order to put this number in perspective, 
this wasted energy represents over 1000 times the total electricity usage in Ireland (and this is just one country's industrial energy waste). Clearly, we cannot continue to waste so much of this valuable resource.

\section{Reduce, Reuse, Recycle}

The heat energy wasted by this industrial sector generally has a temperature of about $100^{\circ} \mathrm{C}$. This may seem relatively high in an everyday scenario, however in industry it is considered a low energy density resource. This is due to the fact that often in chemical reactions and other processes, reacting chemicals and their tanks must be heated to temperatures anywhere up to $400^{\circ} \mathrm{C}$ or even higher. As explained earlier, if we take the temperature of a substance as being representative of its energy density, we can see that the heat energy at $100^{\circ} \mathrm{C}$ can only be used to heat up chemicals and tanks which have temperatures below $100^{\circ} \mathrm{C}$ (picture the radiator example used earlier). Therefore in industry the heat at $100^{\circ} \mathrm{C}$ is simply dumped because no further use can be found for it. Without realising it, you see this happening every time you drive past a factory or plant which has steam billowing from its chimney stacks. This steam represents a large amount of energy, and a lot of coal, oil or gas was probably burnt to originally produce it. The question is how to extract this energy? We have already shown that we cannot use it in its current state, therefore we must alter it in some way.

At this point it may seem logical when we say that what we must do is to increase the temperature of the steam. If its temperature is increased to $200^{\circ} \mathrm{C}$ (or higher) once more, then there is a good chance that the plant will have some reaction or process at about $150^{\circ} \mathrm{C}$ which needs heating. In this way we can then recycle the energy instead of simply discarding it into the atmosphere.

\section{Heat energy recycling methods}

This is the point where my research comes in. We are developing a system which can take in the waste heat energy at $100^{\circ} \mathrm{C}$ and increase its temperature to over $240^{\circ} \mathrm{C}$ once more in order to allow companies to reduce some of their energy losses. Many systems currently exist which can achieve this, the simplest of all being a simple domestic fridge. The problem with using simple systems such as a fridge is that they require a large amount of energy to operate (electricity), and thus this would not make a lot of sense as the sole purpose is to reduce energy consumption. Therefore we are using a technology called "Heat Transformers", which are able to achieve this temperature increase with almost no electrical consumption. This technology has been researched for some time, and positive results have been reported, yet all of these focus on increasing the temperature of the waste heat 
energy by only $20^{\circ} \mathrm{C}-80^{\circ} \mathrm{C}$. These systems work very well for specific applications which only require the temperature of waste heat to be increased slightly, however often much greater increases are needed and therefore this technology cannot be used. This research is attempting to further existing technology so that it is capable of increasing the temperature of waste heat by as much as $120^{\circ} \mathrm{C}-150^{\circ} \mathrm{C}$. This would allow for a much more general applicability of such systems to industry, especially in energy intensive sectors.

\section{Research}

Due to the fact that the system does not require much electrical input, its physical design becomes much more complicated. Thus the starting point for developing a system such as this is the creation of a mathematical model with which its operation may be tested and observed. Once a fully functional model was created, initial parts of my research involved finding the optimum operating conditions for the system, determining how its performance varied when changes are made and how to configure the internal design to allow for a maximum recycling of the waste energy. Different statistical methods are used in order to determine these points of optima so that they may be one-size-fits-all solutions which can be applied to any such system (a generic example is shown in Figure 1).

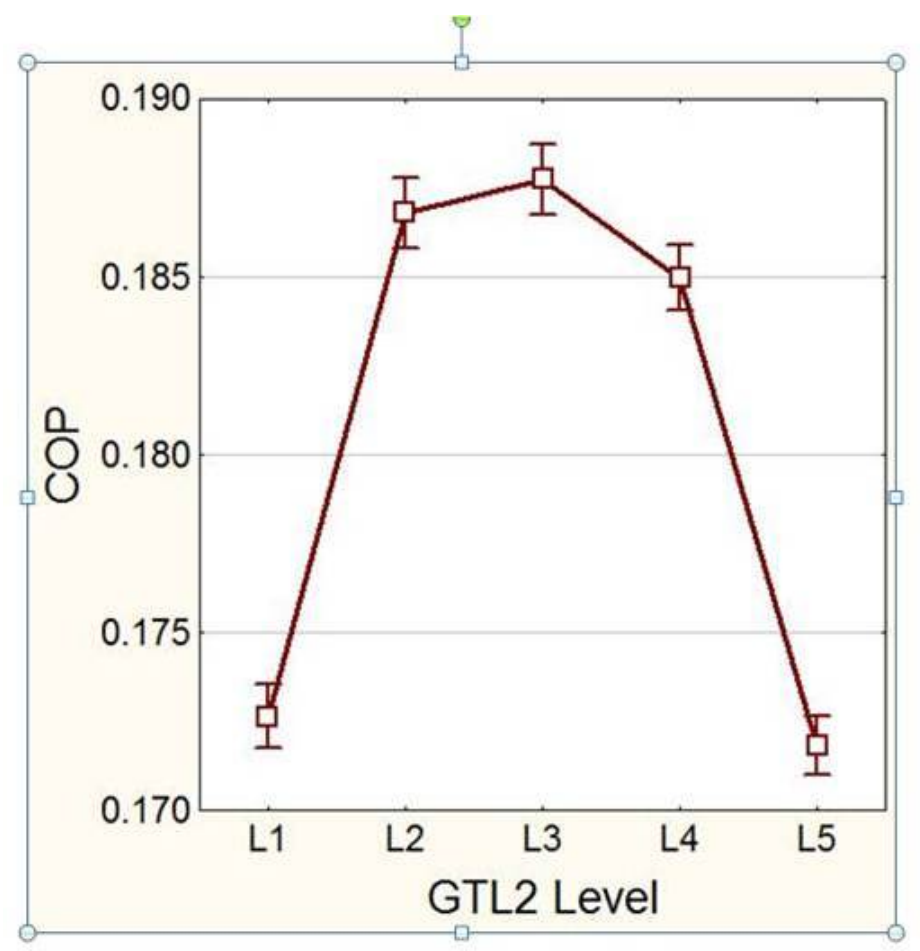

Figure 1: An example of optimisation studies being conducted trying to maximise the fraction of waste heat energy being recycled (COP), while other settings are being varied (such as GTL2 in this example). Image: Philip Donnellan.

Once these initial criteria were developed, the next step was to determine whether any 

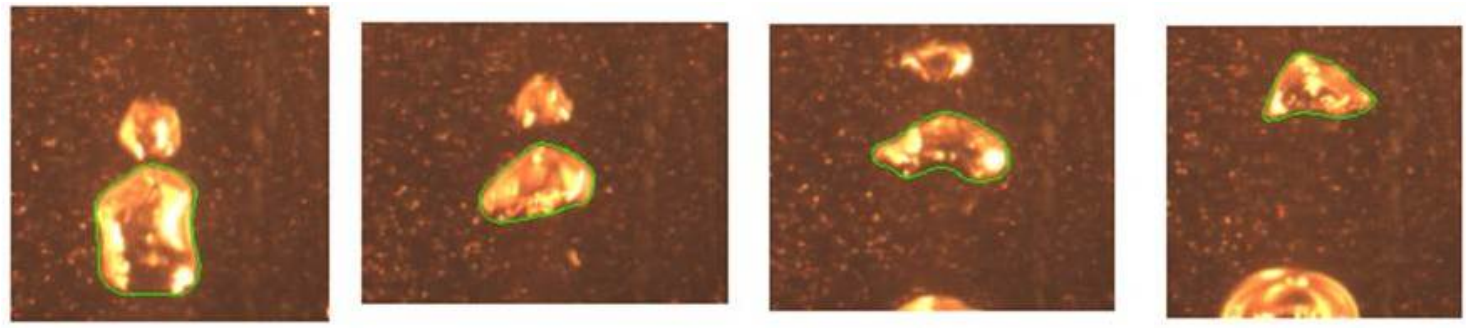

Figure 2: Dissolving Steam bubble being tracked by a high speed camera as part of a series of physical experiments to improve the efficiency of one of the pieces of equipment within the system. Image: Philip Donnellan.

industrial application (i.e.: a factory) would actually benefit from building and installing this system. While increased sustainability may be an attractive proposition for companies, determining whether something is of benefit to a company actually implies estimating the economic benefits and rates of return achievable from such a system. Over the course of this research, we talked to an Irish oil refinery and began to examine their main sources of waste heat energy. The developed system performed very well in the context of simply recycling the energy, as it was capable of increasing the temperature of their waste heat energy from approximately $100^{\circ} \mathrm{C}$ to $230^{\circ} \mathrm{C}$. Therefore from an engineering perspective, the system appears to be highly suitable for application here. The problem which was discovered was that the capital cost of the unit is quite high. This discovery revealed that further work is required in order to address this problem and to reduce the total investment cost of the system. Two possible solutions were identified. The first of these is that the system should simply be used in much bigger factories. Some of the results showed that the more waste heat energy which you have to recycle; the easier it is for the company to make a profit from it. The second solution is that the design of the physical components of the system should be re-examined once more. As part of the system's design, we utilised the most common and well understood pieces of equipment within the system, as companies are generally quite reluctant to accept new or less tested methods. It has now become obvious that for this technology to work, it is vital that such cautions must be abandoned and less conventional designs developed. For this reason we picked a very important piece of equipment within the system and began to run physical experiments with the view to achieving a much more efficient operation.

These experiments examined dissolving a (relatively) cold bubble of steam into a hot very concentrated salt solution. High speed cameras were used to observe many such bubbles and to track their exact shape and size as they dissolved (some images of this have been included in Figure 2 as an example). This information allowed us to model the phenomenon. Results were quite positive with significant potential improvements observed compared to the conventional method used previously. 


\section{What's next?}

All of the work completed so far as part of this research has been an attempt to develop a system which is capable of increasing the temperature of waste heat energy so that it may be reused and recycled within a factory. It is envisioned that this in turn leads to potential reductions in fuel consumption. While this design has been a success from an engineering perspective, for this type of a system to become an attractive industrial option, it needs to be capable of generating acceptable rates of return for the company. This appears to be area which should be of primary focus in future studies. We have shown that to achieve this, the selection and physical design of equipment within the system need to be closely examined to make it more efficient and cost effective. We have started to engage in this process by examining in detail the operation of (what we deemed to be) one of the most important building blocks of the system. This work needs to be conducted for all of the system's pieces of equipment however in order to ensure that this system is capable of achieving industrial acceptance. If positive improvements were to be obtained from such work, then the heat transformer may one day become one of the many tools required to combat future fuel shortages.

Philip Donnellan is a PhD student in the Department of Process and Chemical Engineering, working under the joint supervision of Dr Edmond Byrne and Dr Kevin Cronin. This research has been funded by the Irish Research Council. 